minutes. CPB time was 30 minutes. The patient was discharged on postoperative day 6 . She was doing well at 7-year follow up.

\section{Discussion \\ The long-term results of surgical ASD repair are excellent. The long-term results of all therapeutic percutaneous interventions, including ASD closure, must be compared with the gold standards set by surgery. Early and late complications of the device closure of the ASD have been reported. ${ }^{1-5}$ Although the transcatheter ASD closure is useful in selected patients, it can be associated with life-threatening complications, including cardiac tamponade, de- vice erosion into aorta with aorto-to-atrium fistula formation, and systemic or pulmonary embolization. ${ }^{1-5}$ The patients must be informed of the current results of interventional and surgical approaches and make an informed decision after talking to both interventional cardiologist and cardiothoracic surgeon.}

\section{References}

1. Contrafouris CA, Chatzis AC, Giannopoulos NM, et al. Emergency surgical intervention for runaway atrial septal defect closure devices: a word of caution. J Thorac Cardiovasc Surg. 2006;132:1234-5.

2. Chessa M, Carminatti M, Butera G, Binni RM, Drago M, Rosti L, et al. Early and late complications associated with transcatheter occlusion of atrial septal defects. J Am Coll Cardiol. 2002;39:1061-5.

3. Mello DM, Fahey J, Kopf GS. Repair of aortic-left atrial fistula following the transcatheter closure of an atrial septal defect. Ann Thorac Surg. 2005;80:1495-8.

4. Knirscgh W, Dodge-Khatami A, Balmer C, Peuster M, Kadner A, Weiss M, et al. Aortic sinus-left atrial fistula after interventional closure of atrial septal defect. Catheter Cardiovasc Interv. 2005;66: 10-7.

5. Grayburn PA, Schwartz B, Anwar A, Hebeler RF. Migration of an Amplatzer septal occluder device for closure of atrial septal defect into the ascending aorta with formation of an aorta-to-right atrial fistula. Am J Cardiol. 2005;96:1607-9.

\title{
Reversal of increased pulmonary arterial pressure associated with systemic venous collaterals after tonsillectomy in a Fontan candidate after the Glenn procedure: Impact of obstructive sleep apnea on Fontan circulation
}

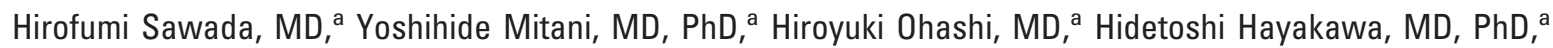

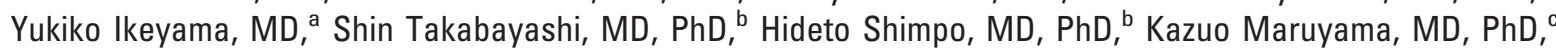
and Yoshihiro Komada, MD, PhD, ${ }^{a}$ Mie, Japan

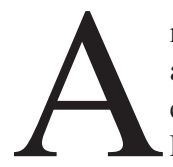

$\mathrm{n}$ increase in pulmonary artery (PA) pressure, associated with the development of systemic venous collaterals, is one of the greatest risks for candidates for the Fontan procedure after the Glenn procedure. ${ }^{1,2} \mathrm{Sim}-$ ple coil embolization for such collaterals may not be sufficient, inducing other collaterals accompanied by persistent high PA pressure with poor outcomes. Mild pulmonary hypertension is a common complication associated with obstructive sleep apnea (OSA). ${ }^{3}$ However, the effects of OSA on pulmonary circulation in Fontan candidates are unknown. We report a patient with a successful Fontan completion in whom high PA pressure associated

From the Departments of Pediatrics, ${ }^{a}$ Thoracic and Cardiovascular Surgery, ${ }^{\mathrm{b}}$ and Anesthesiology, ${ }^{\mathrm{c}}$ Mie University Graduate School of Medicine, Tsu, Mie, Japan.

Received for publication Dec 27, 2006; accepted for publication Jan 2, 2007.

Address for reprints: Yoshihide Mitani, MD, PhD, Department of Pediatrics, Mie University Graduate School of Medicine, 2-174 Edobashi, Tsu city, Mie Pref, 514-8507, Japan (E-mail: ymitani@clin.medic.mie-u.ac.jp).

J Thorac Cardiovasc Surg 2007;133:1371-3

$0022-5223 / \$ 32.00$

Copyright $\odot 2007$ by The American Association for Thoracic Surgery doi:10.1016/j.jtcvs.2007.01.016 with venous collaterals after the Glenn procedure was reversed after a tonsillectomy for OSA after coil embolization.

\section{Clinical Summary}

A 3-year-old boy with pulmonary atresia with an intact ventricular septum presented with progressive cyanosis. The boy had undergone a right modified Blalock-Taussig shunting procedure in the neonatal period and a bidirectional cavopulmonary anastomosis at the age of 6 months. His parents had noticed his dysphagia and nocturnal apnea accompanied by snoring since he was 1 year and 6 months old. Cyanosis and desaturation increased at the age of 2 to 3 years (Figure 1). The patient was admitted to our hospital for the cardiac catheterization. The awake arterial oxygen saturation was $75 \%$. Contrast injection revealed systemic venous collaterals from the innominate vein to the left renal vein (Figure 2, A). The mean pressures in the PA and transpulmonary gradient, measured under controlled mechanical ventilation, were $15 \mathrm{~mm} \mathrm{Hg}$ and $11 \mathrm{~mm} \mathrm{Hg}$, respectively. At the age of 3 years and 6 months, transcatheter coil embolization for systemic venous collaterals was performed in this patient, and beraprost (an orally active prostacyclin analogue) was started. Cardiac catheterization 6 months after coil embolization revealed that the venous collaterals were completely occluded (Figure $2, B$ ) and the systemic saturation was $89 \%$. However, the mean PA pressure was as high as $17 \mathrm{~mm} \mathrm{Hg}$. Symptoms of OSA persisted, and third-degree hypertrophy of the tonsils was found. 


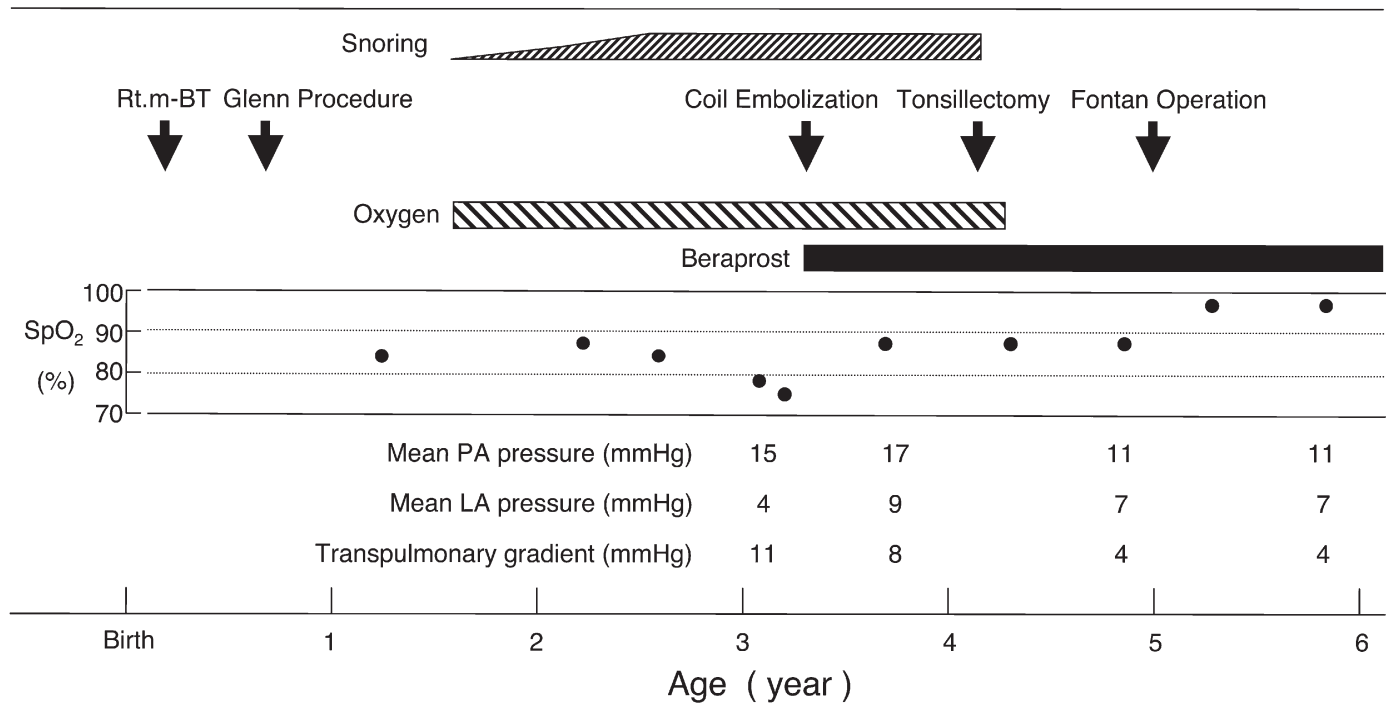

Figure 1. Changes in oxygen saturation levels and pulmonary hemodynamics over time and their association with treatments for cardiovascular disorder and OSA. Rt.m-BT, Right modified Blalock-Taussig; PA, pulmonary artery; $L A$, left atrium.

Because we speculated that increased PA pressure might be related to OSA, the patient underwent tonsillectomy at the age of 4 years and 2 months, and dysphagia and snoring ceased. Cardiac catheterization, 9 months after tonsillectomy, revealed that the venous collaterals remained occluded, and that the mean pressures of PA and transpulmonary gradient were decreased to $11 \mathrm{~mm} \mathrm{Hg}$ and 4 $\mathrm{mm} \mathrm{Hg}$, respectively. At the age of 4 years and 11 months, the patient successfully underwent the Fontan procedure. He was extubated in the operation room, and the postoperative course was uneventful without using inotropic agents or pulmonary vasodilators. Catheterization 11 months after the Fontan operation revealed that systemic saturation was $95 \%$, without obvious venous collaterals (Figure 2, C). The mean PA pressure was $11 \mathrm{~mm} \mathrm{Hg}$. During the 3 -year postoperative follow-up, he has been well without recurrence of cyanosis.

\section{Discussion}

A major finding in this case report is that elevated PA pressure accompanied by systemic venous collaterals was reversed after tonsillectomy in a Fontan candidate after the Glenn procedure. High PA pressure, as demonstrated by cardiac catheterization, was consistent with the appearance of significant venous collaterals. Snoring, a symptom of OSA, preceded progressive cyanosis, which may have coincided with the development of systemic venous collaterals. Furthermore, persistent high PA pressure after coil embolization subsided when snoring ceased after the tonsillectomy. These changes in pulmonary hemodynamic parameters were determined under controlled ventilation. Such improvement in pulmonary parameters was consistently followed by an uneventful postoperative course, with reasonably low PA pressure after the
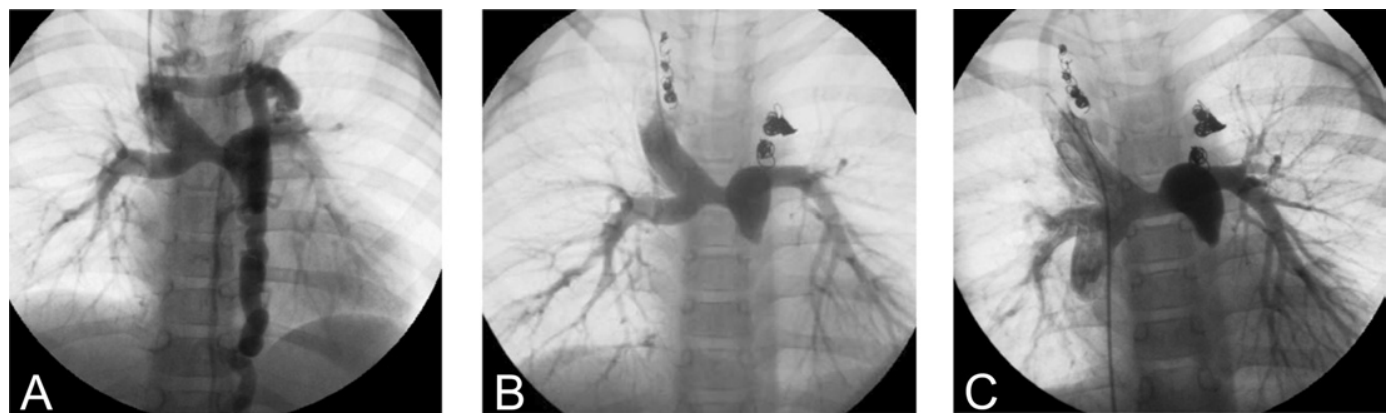

Figure 2. A, Pulmonary angiograms at the age of 3 years and 4 months. Contrast injection in the superior vena cava shows venous collateral drain into the left renal vein. PA index (cross-sectional area of the right and left PAs/body surface area) was $114 \mathrm{~mm}^{2} / \mathrm{m}^{2}$. B, Angiography after transcatheter coil embolization for systemic venous collaterals. The collaterals were completely occluded. PA index was $167 \mathrm{~mm}^{2} / \mathrm{m}^{2}$. C, Angiography $6 \mathrm{months}$ after Fontan operation. PA index was $162 \mathrm{~mm}^{2} / \mathrm{m}^{2}$. 
Fontan procedure. Therefore, the sequence of events is consistent with the hypothesis that the increase in PA pressure may have been caused by obstructive tonsillar hypertrophy and was thereby reversed after tonsillectomy in this patient.

Tonsillar hypertrophy is a common cause of OSA in children. Moderate-to-severe OSA is frequently associated with mild pulmonary hypertension, ${ }^{3}$ which is characterized by mild pulmonary vascular remodeling and endothelial dysfunction, as shown in human and animal studies. ${ }^{4,5}$ Therefore, it is possible that the magnitude of structural and functional alterations in pulmonary vasculature induced by nocturnal desaturation had significant impacts on the Glenn circulation, and that these changes were reversed after tonsillectomy in this case. Furthermore, it is interesting to speculate that such derangement in pulmonary circulation caused by OSA might have similar effects on hemodynamics in patients even after the Fontan procedure. This unique case implies that alleviation of OSA (ie, tonsillectomy) may be an efficacious treatment option for high-risk candidates for the Fontan procedure with high PA pressure after the Glenn procedure.

\section{References}

1. Bartmus DA, Driscoll DJ, Offord KP, Humes RA, Mair DD, Schaff HV et al. The modified Fontan operation in children less than 4 years old. J Am Coll Cardiol. 1990;15:429-35.

2. McElhinney DB, Reddy VM, Hanley FL, Moore P. Systemic venous collateral channels causing desaturation after bidirectional cavopulmonary anastomosis: evaluation and management. J Am Coll Cardiol. 1997;30:817-24.

3. Kessler R, Chaouat A, Weitzenblum E, Oswald M, Ehrhart M, Apprill $\mathrm{M}$, et al. Pulmonary hypertension in the obstructive sleep apnoea syndrome: prevalence, causes and therapeutic consequences. Eur Respir J. 1996;9:787-94. Review.

4. Sajkov D, Wang T, Saunders NA, Bune AJ, Mcevoy RD. Continuous positive airway pressure treatment improves pulmonary hemodynamics in patients with obstructive sleep apnea. Am J Respir Crit Care Med. 2002;165:152-8.

5. Thomas BJ, Wanstall JC. Alterations in pulmonary vascular function in rats exposed to intermittent hypoxia. Eur J Pharmacol. 2003;477:153-61.

\section{Postconditioning in cardiac surgery for tetralogy of Fallot}

Wanjun Luo, MD, Bei Li, MD, Guoqiang Lin, MD, and Rimao Huang, MD, Changsha, Hunan, P.R. China

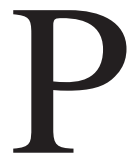

ostconditioning (POC) performed in brief episodes just at the time of ischemic reperfusion can reduce myocardial injury. ${ }^{1,2}$ However, the efficacy of POC in cardiac surgery remains to be determined. We investigated the effect of POC on myocardial protection in children undergoing cardiac surgery for tetralogy of Fallot (TOF).

\section{Patients and Methods}

The hospital ethics committee approved this study, and written informed consent was obtained from all patients' parents. Twentyfour patients aged 1 to 17 years old with TOF were randomized into a POC group $(\mathrm{n}=12$, female/male ratio: $5 / 7)$ and a control group $(\mathrm{n}=12$, female/male ratio: $4 / 8)$. The TOF with pulmonary atresia and absent pulmonary valve were exclusive. Anesthesia was similar in both groups. The operations were performed by the same surgeon (Dr Luo), using hypothermic cardiopulmonary by-

From the Department of Cardiothoracic Surgery, Xiang Ya Hospital, Central South University, Changsha, Hunan, P.R. China.

Received for publication Jan 7, 2007; accepted for publication Jan 17, 2007.

Address for reprints: Luo Wanjun, MD, Department of Cardiothoracic Surgery, Xiang Ya Hospital, Changsha, Hunan, 410008, P.R. China (E-mail: luowanjun@yahoo.com).

J Thorac Cardiovasc Surg 2007;133:1373-4

$0022-5223 / \$ 32.00$

Copyright $\odot 2007$ by The American Association for Thoracic Surgery doi:10.1016/j.jtcvs.2007.01.028 pass $\left(28^{\circ} \mathrm{C}-30^{\circ} \mathrm{C}\right)$ with a hollow-fiber oxygenator and aprotinin $(5 \times$ $10^{5} \mathrm{U} / \mathrm{kg}$ ) administered to the priming volume. The myocardium was protected using intermittent antegrade perfusion of cold blood cardioplegic solution (St Thomas Hospital) in a ratio of 1:4.

POC was started 30

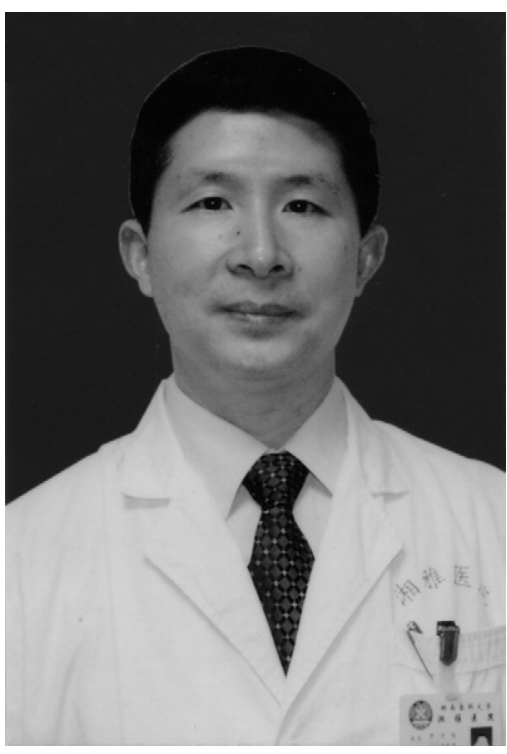

Dr Luo seconds after aortic cross declamping, and the aorta was reclamped for 30 seconds, inducing ischemia; meanwhile, aortic root suction was established during aortic reclamping, and thereafter, the aortic clamp was released for 30 seconds for myocardial reperfusion. This cycle was repeated two times. In the control group, the patients received no aortic reclamping. Blood samples were obtained preoperatively (T1) and 4 (T2), 20 (T3), and 48 (T4) hours after aortic declamping for determination of creatine kinase $\mathrm{MB}$ (CK-MB) and troponin I. All patients were followed for at least 30 days after operation.

The values are expressed as a means \pm standard deviations. The repeated-measures analysis of variance was used to evaluate differences for CK-MB and cardiac troponin I (cTnI) between groups. 